\title{
Would Phoenix Dactyflera Pollen (palm seed) be considered as a treatment agent against Males' infertility? A systematic review
}

Soghra Fallahi ${ }^{1}$, Minoo Rajaei ${ }^{2}, K_{i a n o o s h ~ M a l e k z a d e h}{ }^{1}$, Seyed Mehdi Kalantar ${ }^{3}$

${ }^{1}$ Molecular Medicine Research Center, Hormozgan University of Medical Sciences, Bandar Abbas, Iran

${ }^{2}$ Fertility and Infertility Research Center, Sharyati Hospital; Hormozgan University of Medical Sciences (HUMS), Bandar Abbas, Iran

${ }^{3}$ Unit of Reproductive and Genetic Research, Clinical Centre for Infertility, Yazd Medical Sciences University, Yazd, Iran

Type of article: Systematic review

\begin{abstract}
Introduction: Oxidative stress is a key factor involved in male infertility, which is due to an unnatural increase in environmental free radicals. In the majority of cases, this has a negative effect on a male's ability to impregnate a female. Currently, it is believed that spermatozoa can be protected against the damages induced by oxidative stress by saturating sperm with antioxidants. The antioxidant role of phoenix dactylifera pollen is capable of collecting the reactive oxygen and neutralizing it in and out of body cells. The present research provides a review of the antioxidant roles of phoenix dactylifera pollen on male infertility.

Methods: This research is based on English-Language studies and articles found by comprehensively reviewing electronic databases, websites, books, and academic articles over the last 10 years.

Results: The phenolic compounds of phoenix dactylifera pollen, due to the existing polyphenols, are strong chelators of heavy metals. Therefore, they are effective in eliminating environmental hydroxyl radicals. Moreover, these plants have high capacities of eliminating hydroxyl free radicals, picrylhydrazyl, diphenyl and phoenix dactylifera pollen and also inhibiting glutathione-S-transferase (GST).

Conclusion: Currently, the use of herbal antioxidants to neutralize reactive oxygen species (ROS) and reduce the negative effects of oxidative stress on body cells and tissues has attracted researchers' attention. Various substances, such as flavonoids and catechins, perform their antioxidant role by increasing the concentration of glutathione peroxidase. The final product of this process is an increase in the number of motile sperm, which can have significant effects on fertility.
\end{abstract}

Keywords: infertility, date seed, date palm, male infertility

\section{Introduction}

\subsection{Background}

Infertility is the inability to conceive after one year of intercourse without any contraception, and it occurs about $17 \%$ of marriages. A number of factors have been introduced as the underlying reasons, and one factor is presumed to be the oxidative stress process or the unnatural increase in environmental free radicals (1). Free radicals cause damage to the majority of macromolecules, including lipids, proteins, and nucleic acids. The severity of the damage depends on the exposure time as well as the species. Environmental conditions, such as temperature, oxygen pressure, and the chemical makeup of seminal fluid, including ions, proteins, and antioxidants, have a key role in these damages (2). The oxidative stress process causes damage to the DNA of sperm. Bases and phosphodiester bonds of DNA are prone to peroxidation damages caused by free radicals, which could, in turn, lead to disorders, such as changes in bases, creation of positions with free bases, omission of bases, cross-links, and chromosome rearrangement (3). The lesser amount of reactive oxygen species (ROS) that exists normally in seminal fluid is

\section{Corresponding author:}

Kianoosh Malekzadeh, Department of Molecular Medicine, Faculty of Medicine, Hormozgan University of Medical Sciences (HUMS), Bandar Abbas, Iran. Tel: +98.9176108396, Fax: +98.33337192, Email: keyanoosh@gmail.com Received: June 26, 2015, Accepted: August 17, 2015, Published: December 2015

iThenticate screening: August 07, 2015, English editing: October 27, 2015, Quality control: November 04, 2015

(C) 2015 The Authors. This is an open access article under the terms of the Creative Commons Attribution-NonCommercialNoDerivs License, which permits use and distribution in any medium, provided the original work is properly cited, the use is non-commercial and no modifications or adaptations are made. 
essential for producing sperm. However, in circumstances in which the production speed of these free radicals is higher than flushing out of the inner and outer of body cells, oxidative stress is said to have occurred (1). The excessive production of ROS can cause severe damage to sperm. Recent research has been indicative of high ROS levels in $25-40 \%$ of infertile men (4). The two factors of the intensity of sperm chromatin along with seminal antioxidants would cause DNA protection against the oxidative stress damages (5). If the degree of damage to DNA is small, both the spermatozoa and the egg cell are able to proceed with their role in spite of the damage (6). But higher degrees of damage lead to apoptosis and embryonic cleavage. Heavy damage to sperm DNA leading to embryonic cleavage is reported as the cause of infertility in some cases. (7). It is believed currently that, with the saturation of the sperm's circumference with the help of antioxidants, spermatozoa can be protected against damages induced by oxidative stress (6). Therefore, in recent years, extensive research has been conducted to investigate the effect of natural and synthetic antioxidants (of herbal origins) on the viability of sperm. We investigated the effect of phoenix dactylifera pollen on male fertility. The potential advantages of antioxidants in assisted reproductive technologies have attracted researchers' attention. In this article, we attempted to deduce from various research works whether phoenix dactylifera pollen, as unnatural antioxidants, can improve sperm's viability.

\subsection{Problem Statement}

Free oxygen species could have positive or negative effects on the viability of sperm. This is dependent on their concentration as well and the exposure time. Physiologically, sperm produce a little amount of ROS, which is vital for capacitation, over-activation, acrosome reaction, motility, fertility, and conception. Capacitation is a process that occurs in the female reproductive system during which sperm becomes capable of penetrating the egg cells. In this process, the intracellular calcium levels, ROS, and the activity of the tyrosine kinase enzyme are increased. This leads to an increase in cyclic adenosine monophosphate (cAMP), which, in turn, causes an over-activation of sperm along with their higher motility. Only the capacitated sperm are capable of acrosome reaction. All of these would result in acquiring the ability to fertilize an egg (8). In 2009, Makker et al. showed empirically that sperm with low amounts of hydrogen peroxide can stimulate capacitation, over-activation, the acrosome reaction, and have the ability to penetrate egg cells. Stimulation of the capacitation process and the acrosome reaction has been observed by other free oxygen species, such as nitric oxide and superoxide anions. The lipid peroxidation caused by the low amounts of ROS would lead to transformations of the sperm's membrane, resulting in facilitation of the linkage of the sperm and egg (9). However, an increase in ROS seems to correlate with the sperm's having low motility (2). Oxidative stress can damage mitochondria and make them become sources of ROS production; furthermore the ROS they produce also can result in their further impairment. Therefore, the performance of these organelles would be affected under oxidative stress. Therefore, it could be concluded that mitochondrial inability of energy production under oxidative stress can finally lead to deactivation of glycolysis enzymes and ultimately cause a reduction in the sperm's motility (10). Male infertility can be due to different causes, such as lifestyle, job, and genetics (2), in which the increase of free radicals can have adverse effects on fertility, so creating a balance between free radicals and the body's antioxidants is very important. Future studies should be conducted to study the effects of antioxidants (mainly from herbal sources) in decreasing free radicals and improving male fertility.

\subsection{Objective of research}

The aim of this review was to provide an overview of studies that have been conducted on the effects of phoenix dactylifera pollen on male infertility and its antioxidant effect. In this review, first, the natural antioxidative effects of semen and the antioxidative substances present in palm pollen are discussed. Then, the effects of antioxidative substances present in palm pollen on improving sperm's parameters presented in previous studies are debated.

\section{Material and Methods}

\subsection{General methods}

We searched various English language databases for the period of 2005 through November 2014 to obtain the data for this study. The databases we searched included PubMed, Science Direct, Scopus, Springer, and Google Scholar. Publications were searched in two steps according to exact keywords. The keywords for the first step included male, phoenix dactylifera pollen, date palm, and infertility. The MeSH terms that were used were "Infertility" AND "phoenix dactylifera pollen" AND "date palm" AND "date fruit" OR "date seed." Then, we screened the selected articles using more precise keywords, including male infertility, ROS, and phoenix dactylifera pollen. MeSH terms for this step included "male infertility AND phoenix dactylifera pollen AND ROS." The titles and abstracts of all of the searched articles were assessed for their importance concerning the main point of the review, as well as the inclusion and exclusion criteria. 


\subsection{Inclusion and exclusion criteria}

2.2.1 Inclusion criteria

Inclusion criteria were English language studies, cross-sectional studies, cohort studies, randomized control trials, and meta-analyses, as well as reviews. All applicable studies were evaluated based on titles and abstracts.

2.2.2 Exclusion criteria

Irrelevant studies as well as studies on animals, on patients with anatomical problems in their genitourinary systems, or drugs that affected sperm's parameters, and studies on primary infertility were excluded.

\subsection{Quality assessment}

For the documentation and the design of the value of each article, all parts of the article, including the title, abstract, introduction, methods, results, discussion, conclusions, and other information, were combined with the STROBE (Strengthening the Reporting of Observational Studies in Epidemiology) statement checklist (11). The strength quality of each article was checked based on the STROBE checklist, which included 22 items. Studies with a score of over $60 \%$ were included. Furthermore, the sampling method, the presence of valid tools, and the inclusion and exclusion criteria also were checked. As a result, we identified 10 papers that were deemed to be appropriate for this review, and they are discussed further.

\section{Results}

This review showed that phoenix dactylifera pollen is a very suitable supplement for infertility and can reduce free radicals and increase sperm motility. Many factors are responsible for male infertility, with free radicals being the most important. Five studies showed that an increase in free radicals was responsible for male infertility, and the other five studies showed that 1) free radicals adversely affect male fertility and 2) date pollen has a positive effect on improving sperm's parameters, including motility. The results showed that palm pollen is an effective substance for improving male fertility because it is rich in $\mathrm{B}, \mathrm{Zn}, \mathrm{Se}, \mathrm{Fe}, \mathrm{Mo}, \mathrm{Cu}, \mathrm{Mn}, \mathrm{Co}$, and Ni (12), as well as leucine and lysine, which are amino acids.

\subsection{The natural antioxidants in seminal fluid}

The male reproduction system is abundant in both enzymatic and non-enzymatic antioxidants. The most important non-enzymatic antioxidants in seminal fluid are vitamins $\mathrm{C}$ and E, Q10 co-enzyme, carnitine, uric acid, pyruvate, glutathione, turin, and hypoturin. Catalase (CAT), superoxide dismutase (SOD), and glutathione peroxide (GPX) are among the most important enzymic antioxidants that inhibit the effect of ROS on biomolecules. Enzymic antioxidants accumulate mostly in the spermatozoa with a concentration exceeding those of all other components (13). SOD contains three isoforms that inhibit the effects of superoxide anions. Superoxide dismutase omits the superoxide anions of the inside and outside of cells. It inhibits lipid peroxidation of the plasma membrane. It also inhibits premature activation induced by superoxide radicals before ejaculation (14). Catalase removes the toxic effect of $\mathrm{H} 2 \mathrm{O} 2$ in and out of the cells by converting it to oxygen and water. Moreover, it activates $-\mathrm{NO}$, which induces sperm capacitation (15). The lactoferrin and ceruplolasmin existing in human seminal fluid control the peroxidation of fats in the sperm's membrane and maintains its ability to join the oocyte membrane (13). CAT would lead to a chemical analysis of hydrogen peroxide was water and oxygen molecules. GPX revives hydrogen peroxide and organic peroxides, such as phospholipid peroxides (6). Sperm have a unique status in terms of antioxidant defense. Sperm's cytoplasm contains a small amount of antioxidant enzymes. Moreover, the intra-sperm antioxidant enzymes cannot inhibit membrane peroxidation in the tail and acrosome areas. In natural concentrations, antioxidants have various and useful effects on resolving oxidative stress-induced damage; they eliminate the ROS produced by leucocytes, and they also prevent the cleavage of DNA (16).

\subsection{Phoenix dactylifera pollen}

Until 50 years ago, plants had been the primary source of medical supplies. Date palm pollen (DPP), known scientifically as Phoenix dactylifera pollen, is one of the best-known and sacred fruit trees by people. Phoenix dactylifera L. (also known as Palma major Garsault and Phoenix cycadifolia Hort. Attens ex Regel), which is commonly called date palm, is considered as an important plant in the dry regions of Southwest Asia and North Africa (17-19). Dates are a good source of inexpensive food, and they are important to people in those regions. Dates have religious significance for Muslims worldwide, and they are mentioned frequently in the Holy Quran. They are particularly used to end the daily fasting during the holy month of Ramadan (17, 18, 20). Palm pollen has several pharmacological effects including anti-oxidant and anti-mutagen effects (21). Dates contain nutritious substances, such as various glucoses, unsaturated fatty acids (linoleic acid and oleic acid), and saturated fatty acids 
(stearic acid and palmitic acid) (20, 22, 23). About 15 other minerals are present in dates, including zinc, cadmium, calcium, potassium, vitamins A, B1, B2, C, and niacin (24). Vayalil (2002) showed for the first time that the aqueous extract of dates was an effective scavenger of superoxides and hydroxyl radicals, and it also is effective in inhibiting iron-induced lipid peroxidation as well as protein oxidation in the rat brain homogenate in a concentration-dependent manner (25). Several investigators have reported a strong correlation of pollen antioxidant bioactivity and phenolic compounds $(26,27)$. Later researchers have confirmed these findings with different types of dates $(28,29)$. In 2009, Ye et al. conducted a study to evaluate the antioxidant activity of Tunisian dates. The results indicated that the Korkobbi type of dates had the best lipoperoxyl radical scavenging activity, while the Rotbi type dates worked very well in scavenging hydroxyl radicals (30). Investigations on animals have indicated that oral feeding of p-coumaric acid, which is present in dates, adds to the expression of antioxidant enzyme genes among rat cardiac tissue (29). The observed antioxidant activity of dates is due to their phenolic compounds, anthocyanins, flavonoid glycosides, and procyanidins. The antioxidant activity is reduced by sun-drying and ripening (28, 20). The selenium that is present in dates also has been assumed to contribute to the antioxidant effects. A number of researchers have indicated that this essential trace element exerts its antioxidant function primarily in the form of selenocysteine residues. Evidently, the existence of diverse phenolic compounds and selenium may have led to the observed free radical scavenging and anti-oxidant effects (31). The existing saponin in palm pollen extract stimulates the smooth muscles of penis, and it adds to the motility of sperm and induces erections (32). The existence of some flavonoids, including quercetin, rutin, and $\beta$-amirin, in the pollen grains was shown by AlShagrawi to influence the prevention of the peroxidation of fatty acids in the body. Moreover, carotenoids, such as beta-carotene and lycopene, form a significant component of the anti-oxidant's defense mechanism (33). The plasma membrane is protected by beta-carotenes against lipid peroxidation (34). The water-based extracts from dates also have strong antioxidant activity, which also exists in a wide range of phenolic compounds that are present in dates. These phenolic compounds include p-coumaric, ferulic, and sinapic acids, flavonoids, and procyanidins (17, 35). Palm extracts show the capability of preventing infections that are caused by Pseudomonas phage ATCC $14209-$ B1. They also can totally inhibit bacterial lysis (36). It was later indicated that this effect was caused by interference in part of the lytic cycle of the phage. In addition, date extracts were found to have anti-ulcer (37), anti-cancer (38), anti-diarrheal (39), hepato-protective, anti-mutagenic (40), anti-oxidant (28), aphrodiasiac (25), anti-inflamatory (41), anti-microbial (36), anti-genotoxic (28), anti-hyperlipidemic and nephroprotective activities (42).

\section{Discussion}

Phoenix dactylifera pollen grain is used as a traditional herbal medicine to resolve infertility problems among men. In ancient times, this grain was used in traditional medicine in Egypt to increase and restore male fertility (43). In traditional medicine, it has been used prevalently to treat male infertility. Moreover, the use of a phoenix dactylifera pollen suspension helps to improve sperm counts, motility, and morphology, and it produces a concomitant increase in the weight of the testicles and the epididymis. This occurs because it contains estradiol and flavonoid components, which have a positive effect on the quality of sperm (44). Based on the body of research, phoenix dactylifera pollen was found to be capable of stimulating the gonads (38). Due to having estrogenic compounds, estron is known as an effective stimulant of the gonads, and it has been used to treat infertility in male rats (45). Other active anti-oxidant substances, including flavinoids, phytosterols and carotenoids, have essential role in eliminating free radicals and causing the enhancement of fertility parameters, which can provide an important protective role against oxidative stress (12). Palm pollen grain increases spermatogenesis and DNA formation, by improving the motility and morphology of spermatozoa $(12,13)$. Also it has been shown that various substances and minerals, such as zinc, cadmium, linolenic acid, and palmitic acid, increase the activity of cytochrome P450, thereby increasing the conversion of cholesterol to pregnenolone and increasing the secretion of testosterone (7). Palmitic acid and stearic acid that are present in date palm pollen inhibit 5 alpha reductase enzyme, so less testosterone is converted to dihydrotestesterone, which subsequently increases the concentration of testosterone in the blood (10). Various minerals, including cadmium and zinc, also can enhance the production of testosterone via the biosynthesis of 17-betahydroxy steroid dehydrogenase, which increases the metabolism of steroids (11). All in vitro and in vivo research indicates that there significant improvements in the semen's parameters, such as motility, viability, acrosome reaction, and lipid peroxidation. Only few human studies were available which were conducted in-vitro and the animal studies were conducted in-vivo, so further studies are required to assess the efficacy of palm pollen grain for enhancing male fertility. One of the strengths of this review was that the positive effect of palm pollen is a good anti-oxidant supplement and can neutralize free oxygen radicals, which has yet to be the focus of studies concerning its use as a therapeutic option for treating infertility. Further studies are required to assess the effect of phoenix dactylifera pollen grain on spermatogenesis and its mechanisms. 


\section{Conclusions}

According to previous research, palm pollen could decrease ROS and improve seminal parameters in infertile men. This means that palm pollen could be an effective antioxidant supplement to improve sperm parameters in infertile men. Currently many researchers are interested in investigating the use of herbal antioxidants to neutralize the effect of ROS and to reduce the oxidative stress-induced effects in body cells and tissues. Treatment with the help of antioxidants is a protective defense against oxidative stress, and the goal is to improve fertility parameters. Little research has been conducted to date to determine the therapeutic effects of palm pollen on people. However, considering its special compounds and based on the findings, phoenix dactylifera pollen can be considered as an effective, edible anti-oxidant with the least negative side effects. Due to its significant positive effects, it is highly recommended that additional clinical research be conducted on this plant, concerning its use in the treatment of male infertility and in treating other diseases related to free radicals, such as cancer. As an approach in treatment of male infertility, the pollen also can be taken for use in in-vitro fertilization to improve semen parameters.

\section{Acknowledgments:}

The authors thank the Faculty of Medicine at the Hormozgan University of Medical Sciences (HUMS) for their support.

\section{Conflict of Interest:}

There is no conflict of interest to be declared.

Authors' contributions:

All authors contributed to this project and article equally. All authors read and approved the final manuscript.

\section{References}

1) Halliwell B, Gutteridge J. Oxygen toxicity, oxygen radicals, transition metals and disease. Biochem J. 1984; 219(1): 1. PMID: 6326753, PMCID: PMC1153442.

2) Armstrong JS, Rajasekaran M, Chamulitrat W, Gatti P, Hellstrom WJ, Sikka SC. Characterization of reactive oxygen species induced effects on human spermatozoa movement and energy metabolism. Free Radic Biol and Med. 1999; 26(7): 869-80. doi: 10.1016/S0891-5849(98)00275-5. PMID: 10232830.

3) Zribi N, Chakroun NF, Elleuch H, Abdallah FB, Ben Hamida AS, Gargouri J, et al. Sperm DNA fragmentation and oxidation are independent of malondialdheyde. Reprod Biol Endocrinol. 2011; 9: 47. doi: 10.1186/1477-7827-9-47. PMID: 21492479, PMCID: PMC3098153. Available from: http://www.biomedcentral.com/content/pdf/1477-7827-9-47.pdf .

4) Chen H, Zhao HX, Huang XF, Chen GW, Yang ZX, Sun WJ, et al. Does high load of oxidants in human semen contribute to male factor infertility?. Antioxid Redox Signal. 2012; 16(8): 754-9. doi: 10.1089/ars.2011.4461. PMID: 22149455.

5) Twigg J, Irvine DS, Houston P, Fulton N, Michael L, Aitken RJ. Iatrogenic DNA damage induced in human spermatozoa during sperm preparation: protective significance of seminal plasma. Mol Hum Reprod. 1998; 4(5): 439-45. doi: 10.1093/molehr/4.5.439. PMID: 9665630.

6) Agarwal A, Makker K, Sharma R. REVIEW ARTICLE: Clinical Relevance of Oxidative Stress in Male Factor Infertility: An Update. Am J Reprod Immunol. 2008; 59(1): 2-11. doi: 10.1111/j.16000897.2007.00559.x. PMID: 18154591.

7) Sakkas D, Urner F, Bizzaro D, Manicardi G, Bianchi P, Shoukir Y, et al. Sperm nuclear DNA damage and altered chromatin structure: effect on fertilization and embryo development. Hum Reprod. 1998; 13(suppl 4): 11-9. doi: 10.1093/humrep/13.suppl_4.11. PMID: 10091054.

8) Tvrdá E, Kňažická Z, Bárdos L, Massányi P, Lukáč N. Impact of oxidative stress on male fertility-A review. Acta Vet Hung. 2011; 59(4): 465-84. doi: 10.1556/AVet.2011.034. PMID: 22079708.

9) Makker K, Agarwal A, Sharma R. Oxidative stress \& male infertility. Indian J of Med Res. 2009; 129(4): 357-67. PMID: 19535829.

10) Alvarez JG, Touchstone JC, Blasco L, Storey BT. Spontaneous lipid peroxidation and production of hydrogen peroxide and superoxide in human spermatozoa superoxide dismutase as major enzyme protectant against oxygen toxicity. J Androl. 1987; 8(5): 338-48. PMID: 2822642.

11) da Costa BR, Cevallos M, Altman DG, Rutjes AW, Egger M. Uses and misuses of the STROBE statement: bibliographic study. BMJ open. 2011; 1(1): e000048. doi: 10.1136/bmjopen-2010-000048. PMID: 22021739, PMCID: PMC3191404. 
12) Hassan HM. Chemical composition and nutritional value of palm pollen grains. Global J Biotechnol Biochem. 2011; 6: 1-7. Available from: http://www.idosi.org/gjbb/gjbb6(1)11/1.pdf.

13) Sanocka D, Kurpisz M. Reactive oxygen species and sperm cells. Reprod Biol Endocrinol. 2004; 2(12): 17. PMID: 15038829, PMCID: PMC400757.

14) de Lamirande E, Gagnon C. Impact of reactive oxygen species on spermatozoa: a balancing act between beneficial and detrimental effects. Hum Reprod. 1995; 10(suppl 1): 15-21. doi: 10.1093/humrep/10.suppl_1.15. PMID: 8592032 .

15) de Lamirande E, Jiang H, Zini A, Kodama H, Gagnon C. Reactive oxygen species and sperm physiology. Rev reprod. 1997; 2(1): 48-54. doi: 10.1530/ror.0.0020048. PMID: 9414465.

16) Maneesh M, Jayalekshmi $\mathrm{H}$. Role of reactive oxygen species and antioxidants on pathophysiology of male reproduction. Indian J Clin Biochem. 2006; 21(2): 80-9. doi: 10.1007/BF02912918. PMID: 23105620, PMCID: PMC3453990.

17) Al-Farsi* MA, Lee CY. Nutritional and functional properties of dates: a review. Crit Rev Food Sci Nutr. 2008; 48(10): 877-87. doi: 10.1080/10408390701724264. PMID: 18949591.

18) Dowson V. Date production and protection. Food and Agriculture organization of the United Nations, Room. FAO. 1982; 35: 1-294.

19) Zaid A, Arias Jiménez E. Date palm cultivation. FAO. 1999. Available from: http://www.cabdirect.org/abstracts/20026790572.html.

20) Al-Shahib W, Marshall RJ. The fruit of the date palm: its possible use as the best food for the future? Int J Food Sci Nutr. 2003; 54(4): 247-59. doi: 10.1080/09637480120091982. PMID: 12850886.

21) Biglari F, AlKarkhi AF, Easa AM. Antioxidant activity and phenolic content of various date palm (Phoenix dactylifera) fruits from Iran. Food Chem. 2008;107(4):1636-41. doi: 10.1016/j.foodchem.2007.10.033.

22) Besbes S, Blecker C, Deroanne C, Drira N-E, Attia H. Date seeds: chemical composition and characteristic profiles of the lipid fraction. Food Chem. 2004;84(4):577-84. doi: 10.1016/S0308-8146(03)00281-4.

23) Shariati M, Sharifi E, Kaveh M. The effect of phoenix dactylifera (date-palm) pit powder on testosterone level and germ cells in adult male rats. ZUMS Journal. 2007. Available from: http://www.zums.ac.ir/journal/browse.php?a_id=253\&sid=1\&slc_lang=en.

24) Ali-Mohamed AY, Khamis AS. Mineral ion content of the seeds of six cultivars of Bahraini date palm (Phoenix dactylifera). J Agric Food Chem. 2004; 52(21): 6522-5. doi: 10.1021/jf030518x. PMID: 15479017.

25) Vayalil PK. Antioxidant and antimutagenic properties of aqueous extract of date fruit (Phoenix dactylifera L. Arecaceae). J Agric Food Chem. 2002; 50(3): 610-7. doi: 10.1021/jf010716t. PMID: 11804538.

26) Campos MG, Webby RF, Markham KR, Mitchell KA, Da Cunha AP. Age-induced diminution of free radical scavenging capacity in bee pollens and the contribution of constituent flavonoids. J Agric Food Chem. 2003; 51(3): 742-5. doi: 10.1021/jf0206466. PMID: 12537451.

27) Leja M, Mareczek A, Wy golik G, Klepacz-Baniak J, Czekońska K. Antioxidative properties of bee pollen in selected plant species. Food Chem. 2007; 100(1): 237-40. doi: 10.1016/j.foodchem.2005.09.047.

28) Allaith AAA. Antioxidant activity of Bahraini date palm (Phoenix dactylifera L.) fruit of various cultivars. IJFST. 2008; 43(6): 1033-40. doi: 10.1111/j.1365-2621.2007.01558.x.

29) Al-Farsi M, Alasalvar C, Morris A, Baron M, Shahidi F. Comparison of antioxidant activity, anthocyanins, carotenoids, and phenolics of three native fresh and sun-dried date (Phoenix dactylifera L.) varieties grown in Oman. J Agric Food Chem. 2005; 53(19): 7592-9. doi: 10.1021/jf050579q. PMID: 16159191.

30) Yeh CT, Ching LC, Yen GC. Inducing gene expression of cardiac antioxidant enzymes by dietary phenolic acids in rats. J Nutri Biochem. 2009; 20(3): 163-71. doi: 10.1016/j.jnutbio.2008.01.005. Epub 2008 Jun 10, PMID: 18547798.

31) Ferguson LR, Philpott M, Karunasinghe N. Dietary cancer and prevention using antimutagens. Toxicology. 2004; 198(1): 147-59. doi: 10.1016/j.tox.2004.01.035. PMID: 15138038.

32) Adimoelja A. Phytochemicals and the breakthrough of traditional herbs in the management of sexual dysfunctions. Int J Androl. 2000; 23 (suppl2): 82-4. doi: 10.1046/j.1365-2605.2000.00020.x. PMID: 10849504.

33) Gupta NP, Kumar R. Lycopene therapy in idiopathic male infertility-a preliminary report. Int Urol Nephrol. 2002; 34(3): 369-72. doi: 10.1023/A:1024483520560. PMID: 12899230.

34) Agarwal S, Rao AV. Tomato lycopene and its role in human health and chronic diseases. CMAJ. 2000; 163(6): 739-44. PMID: 11022591, PMCID: PMC80172. 
35) Gu L, Kelm MA, Hammerstone JF, Beecher G, Holden J, Haytowitz D, et al. Screening of foods containing proanthocyanidins and their structural characterization using LC-MS/MS and thiolytic degradation. J Agric Food Chem. 2003; 51(25): 7513-21. doi: 10.1021/jf034815d. PMID: 14640607.

36) Jassim SA, Naji MA. In vitro evaluation of the antiviral activity of an extract of date palm (Phoenix dactylifera L.) pits on a Pseudomonas phage. Evid Based Complement Alternat Med. 2010; 7(1): 57-62. doi: 10.1093/ecam/nem160. Epub 2007 Oct 27, PMID: 18955267, PMCID: PMC2816388.

37) Al-Qarawi A, Abdel-Rahman H, Ali B, Mousa H, El-Mougy S. The ameliorative effect of dates $(<\mathrm{i}>$ Phoenix dactylifera</i> L.) on ethanol-induced gastric ulcer in rats. J Ethnopharmacol. 2005; 98(3): 313-7. doi: 10.1016/j.jep.2005.01.023. PMID: 15814265 .

38) Ishurd O, Kennedy JF. The anti-cancer activity of polysaccharide prepared from Libyan dates $(<\mathrm{i}>$ Phoenix dactylifera</i> L.). Carbohydr Polym. 2005; 59(4): 531-5. doi: 10.1016/j.carbpol.2004.11.004.

39) Al-Taher AY. Possible anti-diarrheal effect of the date palm (Phoenix dactylifera L.) spathe aqueous extract in Rats. Journal of King Saud University Science. 2008; 9(1): 131-8.

40) Bastway Ahmed M, Hasona N, Selemain A. Protective effects of extract from dates (phoenix dactylifera 1.) and ascorbic acid on thioacetamide-induced hepatotoxicity in rats. IJPR. 2010; 7(3): 193-201.

41) Mohamed DA, Al-Okbi SY. In vivo evaluation of antioxidant and anti-inflammatory activity of different extracts of date fruits in adjuvant arthritis. Pol J Food Nutr Sci. 2004; 13(4): 397-402.

42) Al-Qarawi A, Abdel-Rahman H, Mousa H, Ali B, El-Mougy S. Nephroprotective action of Phoenix dactylifera. in gentamicin-induced nephrotoxicity. Pharm Biol. 2008; 46(4): 227-30. doi: 10.1080/13880200701739322.

43) Hassan WA, El-kashlan AM, Mohamed NA. Egyptian date palm pollen ameliorates testicular dysfunction induced by cadmium chloride in adult male rats. J Am Sci. 2012; 8(4): 659-69.

44) Malviya N, Jain S, Gupta VB, Vyas S. Recent studies on aphrodisiac herbs for the management of male sexual dysfunction--a review. Acta Pol Pharm. 68(1): 3-8. PMID: 21485695.

45) Hassan H, Ahmed O, El-Shemy H, Afify A. Palm Pollen Extracts as Plant Growth Substances for Banana Tissue Culture. WJAS. 2008; 4(4): 514-520. 